\title{
Power Flow Control in Transmission Line by Using UPFC
}

\author{
Manish Srivastava ${ }^{1}$, Prakhar Singh $^{2}$, Sandeep Verma ${ }^{3 *}$, Prince Singh ${ }^{4}$ \\ 1,2,3,4 Department of Electrical and Electronics Engineering, Galgotias College of Engineering and Technology, \\ Greater Noida, India
}

\begin{abstract}
The power transfer capacity of electrical transmission lines is typically constrained by the capacity of large signals. Economic considerations such as the high cost of long lines and the income from the supply of additional power make it possible to pursue both economically and technically viable ways to increase the stability cap intensively. On the other hand, the production of efficient ways to use the full thermal capacity of transmission systems. The power industry has already begun to be affected by fast development in the field of power electronics. This is one direct consequence of the idea of aspects of FACTS, which has become possible due to the progress realized in power electronic devices. In theory, the FACTS devices can provide rapid control of real and Var power through transmission line. The UPFC is a FACTS family member with very appealing characteristics. Many parameters can be independently controlled by this unit. An alternative means of minimizing transmission system oscillations is given by this unit. The choice of input signals and the adopted control strategy for this system in order to dampen power oscillations in an efficient and robust manner are an important issue. In order to achieve the maximum desire effect in solving the first swing stability problem, the UPFC parameters can be regulated. In bulky power transmission systems with long transmission lines, this problem arises. A MATLAB Simulink Model with UPFC to test the efficiency of the electrical transmission system is considered in this paper. The main purpose of this analysis paper is to research different studies performed in the past to minimize UPFC transmission line losses.
\end{abstract}

Keywords: UPFC, FACTS, STATCOM, SSSC.

\section{Introduction}

As high-power semiconductor technology continues to grow rapidly, it is now we are able to monitor electrical power systems by using electronic power devices. Such equipment is an evolving technology known as FACTS, which (flexible alternating current transmission systems). In 1988, N.G Hingorani presented its first concept (FACTS) as a very common and significant device for power systems. [1]. There are a range of advantages to FACTS technology, such as better control of power flow, it ensures safe loading of current transmission circuits, dampens power system oscillations, has less environmental effects, and is a smaller amount costly than another substitute transmission system reinforcement strategy.

Synchronous Compensator (STATOM), Static Series Capacitor (SCSC), Static Series Compensator (SSSC), Unified
Power Flow Controllers (UPFCs), Thyristor Switched Capacitor (TSC), Thyristor Switched Capacitor (TSC), Thyristor Switched Capacitor (TSC), Thyristor Switched Capacitor (TSC), Thyristor Switched (TSC). Many FACTSdevices have been introduced for different power system applications.

UPFC is the most flexible tool used in FACTS devices. It is not only capable of performing, but it is also willing to do so. The static synchronous compensator (STATCOM), thyristor switched capacitor (TCS), thyristor controlled reactor (TCR), and phase angle regulator functions provide more flexibility by combining several of the above control functions. UPFCs primarily regulate active and VAR power flow by injecting the voltage by series manner into the transmission line, with phase angle and magnitude of voltage being independently variable. Power flow control, both reactive and actual, can allow power to flow on designated routes and load transmission lines near their thermal limits, as well as improve transient and low-power system signal stability.

UPFC integrates two supplementary FACTS devices: STATCOM and SSSC. Both are voltage source inverter (VSI). One is shunt connected and other series connected to transmission line.

\section{Unified Power Flow Controller}

In today's generation, UPFC is one of the most versatile platforms for multi-functional FACTS. UPFC can be regulated transmitted power by adjusting three power transmission line parameter, namely the impedance, phase angle and voltage of the transmission line.

UPFC is a voltage source converter that combines two voltage source converters, a shunt and a series converter, and connects them through a common dc connection. In addition to providing the dc power provided by both inverters as illustrated in fig. 1, shunt converters (converter-1) or static synchronous compensators (STATCOM) supply reactive power to the ac device, while serial converters (converter-2) or SSSC add the operated tensile immensity range. Every single one of the divisions It consists of an electronic converter for transformers and control. A common dc capacitor was shared by those two voltage source converters. In between the Ac terminal of two 
converters the true power will flow freely in either direction. In this regard, the key feature of converter 2 is to inject the $\mathrm{AC}$ voltage $\mathrm{Vs}$ at the device frequency with the not fixed magnitude $|\mathrm{Vs}|,(|\mathrm{Vs}| \leq 0 \leq|\mathrm{Vs}|) \max$ ) and the phase angle (which lies between 0 and $2 \pi$ ) in series. Converter-1, on the other side, is primarily used to supply the actual power required by converter- 2 by the common dc link.

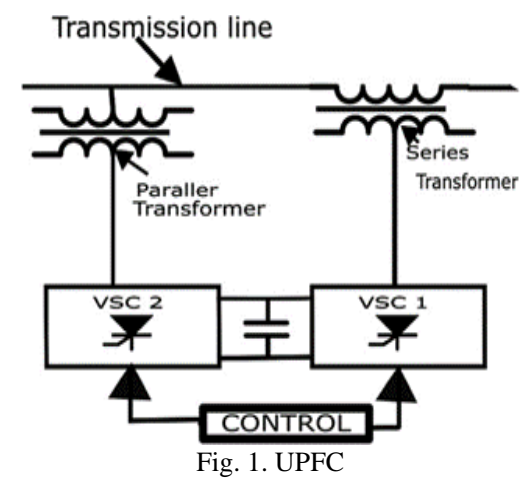

This dc condenser is generally limited in its capacity for storing electricity. You may choose separately the reactive power of series or shunt converter to increase the fluidity of controlling of power flow.

\section{UPFC's Voltage Source Converter}

\section{A. STATCOM}

The term STATCOM refers to as Static VAR Compensator which is shunt connected and its output current can be regulated regardless of the Alternating Current system voltage, whether capacitive or inductive. The AC output voltage of the voltage supply converter is controlled to ensure that there is enough reactive current flow for all $\mathrm{AC}$ bus voltages. If required, the voltage supply converter is monitored so that it is appropriate for being necessary flow of reactive current for all voltage of Alternating Current bus.

The voltage of DC capacitor is inevitably balanced to assist as the voltage source of the converter. The aim of STATCOM was to service as an active filter to engross system harmonics. Shown Fig. 2, the diagram for STATCOM beyond of an energy storing unit.

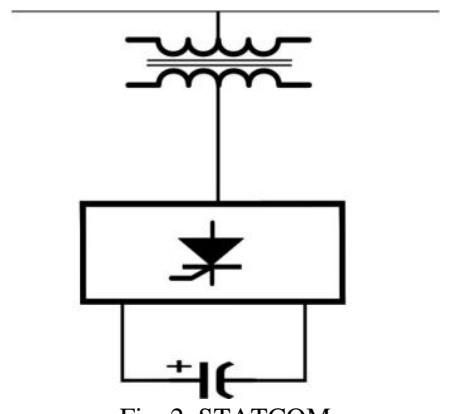

Fig. 2. STATCOM

\section{B. SSSC}

The Static Synchronous Series Generator operates in quadrant mode, allowing it to independently increment or decrement the total VAr voltage drop in distribution line, thus governing the transmitted electric power without the use of an external power source. The SSSC may provide transient energy storage or power absorption devices to improve zestful performance by temporarily increment or decrement the total actual voltage fall along the line.

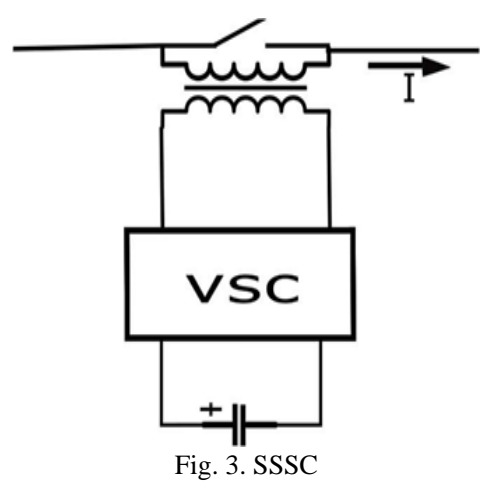

\section{Control Unit}

\section{A. Shunt Converter Control}

Fig. 4, represent the block diagram of shunt converter. A regulated current from the device is drawn by the shunt converter. $I_{p}$, which is $I_{p}$, is one part of this current Automatically performed by the necessity to match the actual power delivered to the series connected converter across the Direct current connection. DC capacitor voltage controls by response control, this power balance is implemented.

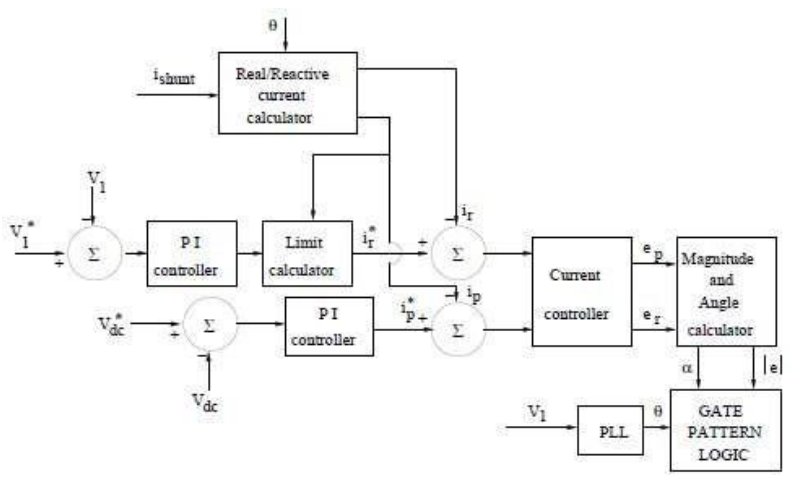

Fig. 4. Control circuit

The other half of the shunt converter current $\left(\mathrm{I}_{\mathrm{r}}\right)$, which is adjustable in the same way as STATCOM is. This can be set to one of two modes of operation. Such instances are as follows:

Control mode of the VAR in which the inductive or capacitive command specifies the relationship of the reactive present. Current transformer (CT) produces feedback signal and are usually found on the transformer's (stage down) coupling bushings.

Self-voltage control mode, with a feedback voltage controller output deciding the relation to reactive current, including the drop characteristic (in case of a SVC or a STATCOM). Potential transformer (PT) measure V1 is the voltage at the substation that feeds the transformer and provides voltage feedback. 


\section{B. Series converter controls}

Fig. 5 shows the block diagram of the converter sequence is illustrated. A serial injected voltage is defined to ensure flow of necessary current (phasor) even when the device is disturbed in this control mode. (The power and reactive power modulation is unless the system control dictates).

Although normal conditions are needed for the instruction of the apparent power flow in the line, eventuality conditions necessitate the use of a control unit to contribute to device constancy by oscillations in damping power.

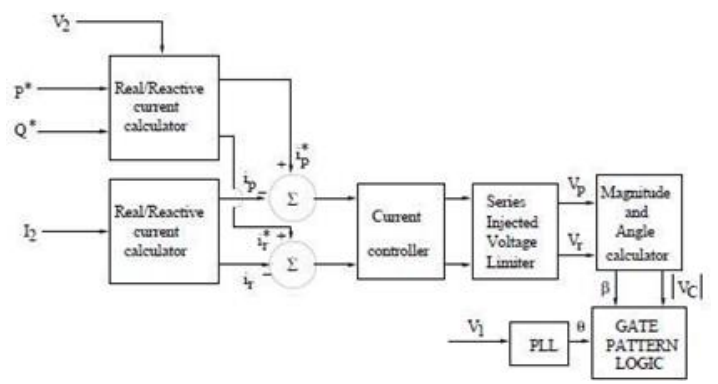

Fig. 5. Series converter control

The following are the various voltage control modes for the series:

1. Direct voltage injection mode in which, according to the reference input, the converter simply generates a voltage phasor. This is a special case where the reactive voltage is the desired voltage and the line current is in quadrature.

2. The injected voltage is phase shifted by an angle indicated by the reference input relative to the voltage in this mode of emulation.

3. Automatic mode of power flow control in which the reference inputs define the active power $(\mathrm{P})$ and VAR (Q) necessary at the appropriate transmission line location.

\section{Simulink Modelling}

The control and simulation of UPFCs using the MATLAB environment have been addressed in this section. Systems simulation work has been conducted for the Multi Machine (3 machines 9 bus). In this case it has been tested for various responses to the existence of three-phase failure and different system parameters. In the course of the investigation, failure clearing, fault positioning and its impact on system stability lead to knowledge of variance in load angle. The IEEE system, with its 3-machine 9-bus system and standard parameter values, was used as a test case. Angle of phase shifter. Injected voltage is phase shifted by the angle indicated by the reference input relative to the voltage in this mode of emulation. This model does not attach to the compensating system. It gives a temporary system answer in the event of a malfunction. Fig. 6 shows in the IEEE 3-Machine 9-Bus model based on MATLAB/Simulink with UPFC and various phase fault forms between bus 5-7.

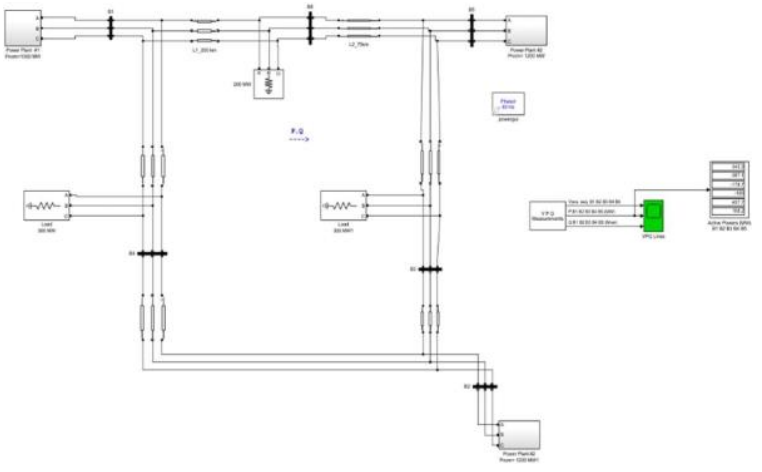

Fig. 6. IEEE Platform 9 bus framework without UPFC MATLAB/Simulink based model

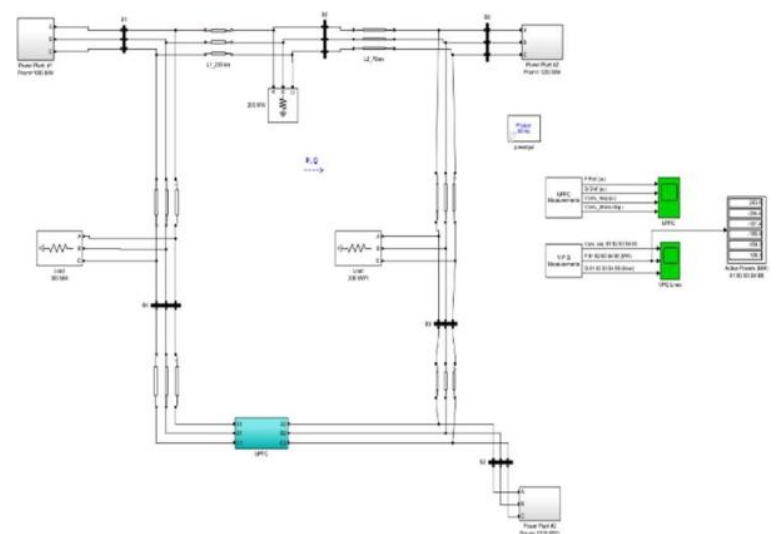

Fig. 7. IEEE Platform 9 bus framework with UPFC MATLAB/Simulink based model

\section{Result}

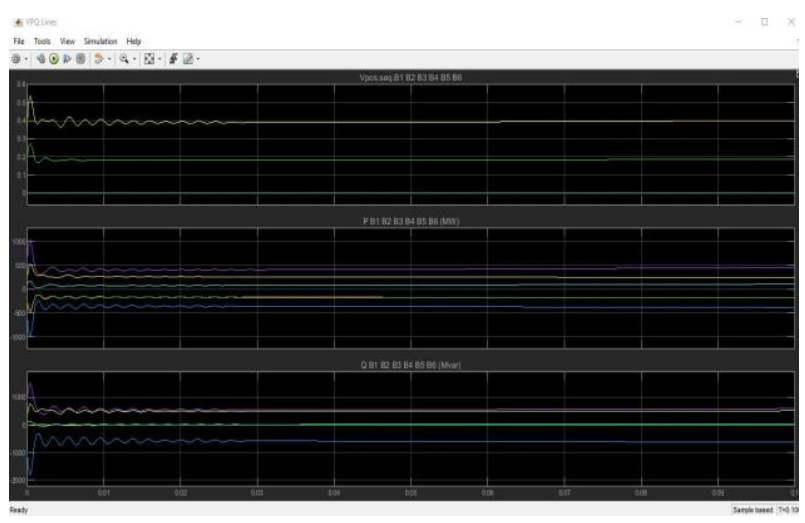

Fig. 8. Voltage profile when UPFC not connected

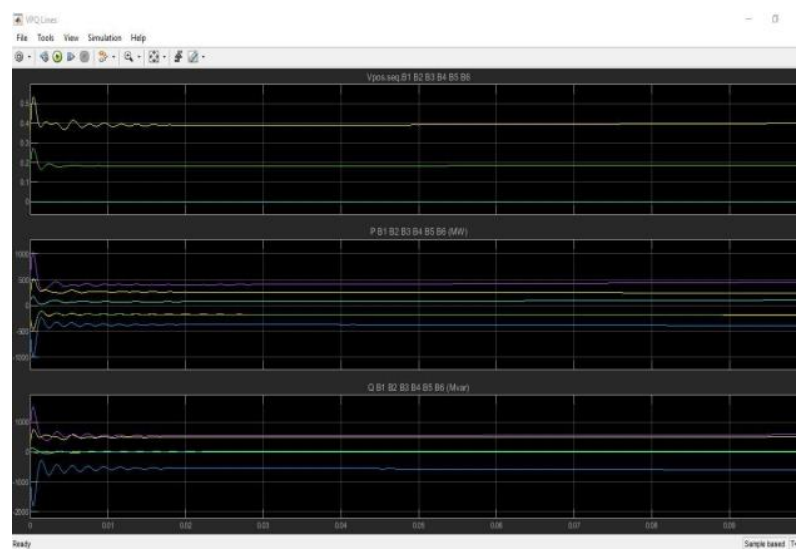

Fig. 9. Voltage profile when UPFC connected 


\section{A. Simulation result for power transfer capability}

Table 1

Voltage

\begin{tabular}{|l|l|l|}
\hline BUS & \multicolumn{1}{|c|}{ WITHOUT UPFC } & WITH UPFC \\
\hline B1 & 0.3997 & 0.3997 \\
\hline B2 & $2.63 \mathrm{e}-14$ & $4.517 \mathrm{e}-12$ \\
\hline B3 & $5.086 \mathrm{e}-15$ & $2.859 \mathrm{e}-12$ \\
\hline B4 & 0.1858 & 0.1866 \\
\hline B5 & $1.719 \mathrm{e}-14$ & $7.773 \mathrm{e}-12$ \\
\hline B6 & $1.081 \mathrm{e}-14$ & $4.259 \mathrm{e}-12$ \\
\hline \multicolumn{2}{|c|}{ VOLTAGE $(k V)$} \\
\hline
\end{tabular}

Table 2

Active power

\begin{tabular}{|l|l|l|}
\hline BUS & \multicolumn{1}{|c|}{ WITHOUT UPFC } & \multicolumn{1}{|c|}{ WITH UPFC } \\
\hline B1 & 242.2 & 243.6 \\
\hline B2 & -387.1 & -394.4 \\
\hline B3 & -178.7 & -181.4 \\
\hline B4 & -183 & -185.9 \\
\hline B5 & 457.7 & 459.3 \\
\hline B6 & 108.2 & 108.3 \\
\hline
\end{tabular}

ACTIVE POWER (MW)

Table 3

Reactive power

\begin{tabular}{|l|l|l|}
\hline BUS & \multicolumn{1}{|c|}{ WITHOUT UPFC } & \multicolumn{1}{|c|}{ WITH UPFC } \\
\hline B1 & 513.5 & 512.9 \\
\hline B2 & -629.1 & -603.5 \\
\hline B3 & 2.182 & 1.175 \\
\hline B4 & 22.23 & 21.51 \\
\hline B5 & 588.9 & 588.5 \\
\hline B6 & -2.554 & -2.595 \\
\hline
\end{tabular}

REACTIVE POWER (MW)

\section{Conclusion}

FACTS equipment that is traditionally used in the power system for voltage profile enhancement controls actual and reactive power flow and improves transmission capability. With the aid of load flow, the steady state UPFC injection model is incorporated into the IEEE-9 bus system. It has been discovered that incorporating UPFC into the above device reduces system losses. Each bus's voltage profile has also increased. They plot and compare the bus voltage with and without UPFC.

\section{References}

[1] Anderson, P.M., Faud, A.A, Power system control and stability. Galgotia Publication, 2009.

[2] Concordia, C., "Effect of steam turbine reheat on speed-governor performance.” ASME J. Eng. Power, vol. 81, pp. 201206, 2007.

[3] Kirchmayer, L.K., Economic Control of Interconnected Systems, Wiley, New York, 2009.

[4] Young, C.C., and Webler R.M., "A new stability program for predicting the dynamic performance of electric power systems", Proc. Am. Power Conf., Volume-29, (1967): pp. 1126-1139.

[5] Byerly, R.T, Sherman D.E., Stability program data preparation manual. Westinghouse Electric Corp., 2006.

[6] Crary S.B., Power System Stability, Volume.2, Wiely, New York, 2017.
[7] Ewart, D.N., Flexible AC transmission systems (FACTS) scoping study, 2015.

[8] Hingorani, N.G.: 'High power electronics and flexible AC transmission system', IEEE Power Eng. Reo., July 2018.

[9] Maliszewski, R.M., Power flow in highly integrated transmission network, CIGRE, 2009.

[10] Christl, N. Advanced series compensation with variable impedance, EPRI Workshop on FACTS, Cincinnati, Ohio, USA, November 2007.

[11] Gyugyi, L., "Reactive power generation and control by Thyristor circuits", IEEE Trans. Ind. Appl., 2010.

[12] Sumi, Y., "New static VAr control using force-commutated inverters", IEEE PES Winter Power Meeting, Volume 38 (2013).

[13] Gyugyi, L., "Advanced static VAr compensator using turn-off thyristors for utility applications", CIGRE, 2012.

[14] Gyugyi, L, "Solid-state control of electric power in AC transmission systems", International symposium on electric energy converters in power systems, Italy, 2016.

[15] Erinmez, LA., "Static VAr compensators", Working Group 38-01. Task Force No. 2 on SVC, CIGRE, 2014.

[16] Wood, P., "Study of improved load tap changing for transformers and phase-angle regulators", EPRI Report EL-6079, Project 2763-1, 2007.

[17] Hingorani, N.G., "FACTS-flexible AC transmission system", IEE 5th international conference an AC and DC transmission, London.

[18] Round, S.D., Yu, Q., Norum, L.E., and Undeland, T.M., "Performance of a unified power flow controller using a d-q-control system", IEE conference on AC and DC transmission, London, Volume 29, April-May 2009

[19] Liu, J.Y., Song, Y.H., and Foss, A. M, "Simulation of the PWM UPFC Using EMTP”, IEEE conference on AC and DC power transmission", Volume 29, April-May 2018.

[20] Lombard, X., and Therond, P.G, "Control of unified power flow controller: comparison of methods on the basis of a detailed numerical model”, IEEUPES Summer Meeting, July-August 2013.

[21] Schauder, C., and Mehta, H., "Vector analysis and control of advanced static Var commnsators", IEE Proc. C, Volume 37, 2003.

[22] Gyugyi, L., "A unified power flow control concept far flexible AC transmission system", IEEE 5th international conference on AC and DC transmission, Sept. 2004

[23] Gyugyi, L., "The unified power flow controller: a new approach to power transmission control", IEEE Trans., Power Deliv., Volume 10, 2009.

[24] Maheshwari, A., and Ngo, D.T., "Synthesis pulse width modulated waveforms with selective harmonic elimination", IEEE Tram. Power Electron, Volume 8, 2017.

[25] Makombe, T., An investigation of a unified power flow controller, Ph.D. thesis, UMIST, UK, 2009.

[26] Gyugyin L., Schauder, C.D., Williams, S.L., Rietman, T.R., Torgerson, D. R., Edreis, A., "The Unified Power Controller: Anew approach to Power T Transmission Control", IEEE Trans. On Power Delivery, vol. 10, no.2, pp.1085-1097, April 2008.

[27] Gyugyi, L., "Unified power flow concept for flexible AC transmission systems", IEE Proc-C, vol. 139, no.4, pp. 323-332, July 2002.

[28] Povh, D. Mihalic, R. Papic, I., FACTS equipment for Load Flow in High Voltage Systems, Cigre Symposium, Power Electronics in Power Systems, Tokyo, May 2006.

[29] Mihalic, R, Zunko, P., Povh, D., Modeling of Unified Power Flow Controller and its impact on power oscillation damping, Cigre Symposium, Power Electronics in Power Systems, Tokyo, May 2009.

[30] Padiyar, K. R., Power System Dynamics- Stability and Control, John Wiely and Sons (SEA) Pte Ltd, Singapore, 2004.

[31] Schauder, C., Mehta, H., "Vector Analysis and Control of Advanced Static Var Compensator “, IEE Proc.-C, vol. 140, no.4, pp. 299-306, July 2012.

[32] Walker, Loren H., "10-MW GTO Converter for Battery Peakin Service", IEEE Trans. On Industry Applications, vol. 26, no. 1, pp. 63-72, Jan/Feb 2013

[33] Padiyar, K. R., Uma Rao, K., "A Control Scheme for Unified Power Flow Controller to improve Stability of Power System", National Power Systems Conference, India, Dec. 2016. 